\title{
The Effect of Omega/Heparin Association on the Obstetric Outcome of Pregnant Women with Thrombophilia: A Pilot Study
}

\author{
Marcelo Lopes de Souza Mendes ${ }^{1,4}$, Lucas Campos Amaral ${ }^{1,4}$, Daniel Henrique de Siqueira Dornelas ${ }^{1,4}$, Lucas \\ Palhares Baeta Duarte ${ }^{1,4}$, Giovanna Carvalho Silva ${ }^{1,4}$, Mariana Pinto Sirimarco ${ }^{2,4}$, Alexander Cangussu Silva ${ }^{2,4}$, \\ Clarissa Rocha Panconi ${ }^{2,4}$, Larissa Milani Coutinho ${ }^{2,4}$, Patrícia de Oliveira Lima ${ }^{3,4}$, Sirleide Corrêa Rangel ${ }^{3,4}$, \\ Flávia Lima Miranda ${ }^{3,4}$, Maria Luiza Braga Leal ${ }^{3,4}$, Geovana Tiango Gabriel ${ }^{3,4}$, Gabriel Duque Pannain ${ }^{2,4}$, Marcus \\ Gomes Bastos ${ }^{3}$, Juliana Barroso Zimmermmann ${ }^{1,2,4^{*}}$
}

${ }^{1}$ Women's Health Discipline, Medical School of Barbacena, Barbacena, Minas Gerais, Brazil; ${ }^{2}$ Maternal-Infant Department, Medical School, Federal University of Juiz de Fora, Juiz de Fora, Brazil; ${ }^{3}$ Gynecology and Obstetrics Service - CAS - University Hospital (UH), Federal University of Juiz de Fora, Juiz de Fora, Brazil; ${ }^{4}$ Obstetric High-Risk Group, Brazil

\begin{abstract}
Introduction: It is possible assuming that thrombophilias can change the optimal placental function, as well as lead to infarctions, impaired maternal-fetal exchange mechanisms and even to fetal death. Placental hypoxia determines a vicious cycle comprising oxidative stress, vasoconstriction and impaired fetal oxygenation. Prophylactic heparin use throughout pregnancy has been recommended in some thrombophilia cases because it acts on the coagulation cascade. However, although heparin does not cross the placental barrier and is safe for the fetus, not all patients can use it. Its administration route (parenteral) is not practical and even its prophylactic use is not necessarily harmless, as seen in different thrombocytopenia, gastrointestinal and cerebral bleeding reports. Thus, finding clinical alternatives for these pregnant women would help significantly improving the current medical practice. The use of essential fatty acids (EFAs) is a new perspective that appears to be applicable in daily medical practice, because it facilitates the blood flow and tissue oxygenation, since they reduce vascular resistance and platelet aggregation. Methods: This study is a randomized, controlled, unblind, parallel, three-arm, open-label prevention trial conducted with pregnant women diagnosed with thrombophilia, who were treated in the Obstetrics Services of University Hospitals belonging to UFJF and to Medical School of Barbacena. All the patients were divided in two groups: Group 1=Hereditary thrombophilia patients who used $40 \mathrm{mg}$ of heparin/day (enoxaparin) from the 6th pregnancy week on; Group 2 Patients with acquired or hereditary thrombophilias associated with risk factors for preeclampsia, according to ACOG19 (chronic kidney disease, previous diabetes mellitus, chronic arterial hypertension and collagenoses).

Results: The current study assessed 38 pregnant women. Patients' mean age was $32.9 \pm 5.0$ years. The pulsatility index in the second gestational trimester ( 24 to 28 weeks) was compared based on treatments. Patients treated with the $\mathrm{H}+\mathrm{ASA}+$ omega association recorded the lowest pulsatility index; however, there was not statistically significant difference between groups ( $p>0.05$ ). Uterine artery resistance index in the second gestational trimester ( 24 to 28 weeks) was also compared based on treatments. Patients treated with the $\mathrm{H}+\mathrm{ASA}+$ omega association recorded the best resistance index, however, there was not statistically significant difference between groups ( $>0.05)$. The group treated only with heparin recorded the lowest fetal weight, although there was not statistically significant difference between groups.

Conclusion: Our results are preliminary, and a crude evaluation of the data shows a decrease in the pulsatility and resistance indices of the uterine art. With the increase of patients in the analysis, we hope that the statistical results can demonstrate this improvement of placental flow.
\end{abstract}

Keywords: Prenatal care; Thrombophilia; Heparin; Acetylsalicylic acid

Correspondence to: Dr. Juliana Barroso Zimmermmann, Maternal-Infant Department, School of Medicine, Federal University of Juiz de Fora, Juiz de Fora - MG, Brazil, Tel: +5532988483345; E-mail: julianabz@uol.com.br

Received: September 04, 2019; Accepted: September 10, 2019; Published: September 17, 2019

Citation: de Souza Mendes ML, Amaral LC, de Siqueira Dornelas DH, Duarte LPB, Silva GC, Sirimarco MP, et al. (2019) The Effect of Omega/ Heparin Association on the Obstetric Outcome of Pregnant Women with Thrombophilia: A Pilot Study. Clinics Mother Child Health. 16:332. doi: $10.35248 / 2090-7214.19 .16 .332$

Copyright: ( 2019 de Souza Mendes ML, et al. This is an open-access article distributed under the terms of the Creative Commons Attribution License, which permits unrestricted use, distribution, and reproduction in any medium, provided the original author and source are credited. 


\section{INTRODUCTION}

Pregnancy increases procoagulant factor levels and decreases natural coagulation inhibitors. The aim of such hypercoagulability state is to protect women in case of bleeding, whether at childbirth or due to complications such as miscarriage. However, such coagulant state can worsen thromboembolic diseases and placental insufficiency [1].

In addition to pregnancy-related changes, abnormalities associated with hyperactivity in the genetically encoded blood coagulation system, such as hereditary thrombophilia (HT), can also affect pregnant women. Thus, pregnant women with genetically inherited thrombophilia would present a series of factors favoring thrombosis development [2].

There is no consensus on whether hereditary thrombophilias determine unfavorable maternal and fetal outcomes, although some studies have shown such association [3-7]. According to a recent study carried out at Medical School of Barbacena [1], hereditary thrombophilias were associated with unfavorable obstetric outcomes and should be taken into consideration at obstetric clinics. Among such outcomes, one finds protein S deficits, which are associated with miscarriages, as well as antithrombin III and protein $\mathrm{C}$ deficits, which are associated with fetal death and with the tendency of pregnant women with hyperhomocysteinemia to have preeclampsia. In addition, MTHFR mutation was associated with history of Hellp syndrome and with preeclampsia in case of homozygous mutation [1]. Thus, unfavorable obstetric outcomes such as placental abruption (PA), intrauterine fetal death, prematurity, intrauterine growth restriction (IUGR), low birth weight and miscarriages can result from maternal thrombophilias [1].

Placental hypoxia determines a vicious cycle comprising oxidative stress, vasoconstriction and impaired fetal oxygenation. Thus, when it comes to thrombophilia, it is necessary taking into consideration two different contexts: the maternal context, which focuses on enabling thrombosis, stroke and pulmonary embolism prophylaxis; and the fetal context, which focuses on enabling proper fetal growth to avoid early or late fetal losses [1].

Prophylactic heparin use throughout pregnancy has been recommended in some thrombophilia cases because it acts on the coagulation cascade - i.e., it interacts with antithrombin to form a complex that inactivates coagulation factors II, IX and X; most significantly with thrombin, in order to decrease complement activation and to reduce the risks of stroke, deep vein thrombosis (DVT) and pulmonary embolism (PE) development. Thus, it is mainly indicated to pregnant women diagnosed with chronic atrial fibrillation and atrial dilation, to patients with metallic prosthetic valves and to those who experienced recent arterial thrombosis and stroke events; however, some studies have also shown that heparin use had beneficial effects on the prophylaxis of unfavorable fetal outcomes, mainly on the risk of miscarriage and intrauterine fetal death events in pregnant women with thrombophilias [8].

However, although heparin does not cross the placental barrier and is safe for the fetus, not all patients can use it. Its administration route (parenteral) is not practical and even its prophylactic use is not necessarily harmless, as seen in different thrombocytopenia, gastrointestinal and cerebral bleeding reports $[1,9,10]$. Thus, finding clinical alternatives for these pregnant women would help significantly improving the current medical practice. The use of essential fatty acids (EFAs) is a new perspective that appears to be applicable in daily medical practice, since it reduces prostaglandin E2 (proinflammatory) metabolite production, decreases thromboxane A2 (potent platelet aggregation agent and vasoconstrictor) concentrations, reduces leukotriene B4 (leukocyte inflammation, chemotaxis and adherence inducer) formation, as well as increases thromboxane A3 (weak platelet aggregation agent and vasoconstrictor), prostacyclin PGI3 (vasodilator and platelet aggregation inhibitor) and leukotriene B5 (weak inflammation inducer and chemotactic agent) concentrations. These actions appear to facilitate blood flow and tissue oxygenation, since they reduce vascular resistance and platelet aggregation [11-14].

Alpha-linolenic (ALA - omega 3) and linoleic (LA - omega 6) acids stand out among fatty acids. ALA is converted into EPA and DHA, whereas LA is converted into arachidonic acid (AA). Nowadays, these acids are already prescribed to pregnant women, mainly DHA. It happens because DHA is an essential component of cell membranes, mainly the ones in the brain and retina; thus, it plays a key role in the development of the central nervous system, in children's motor and visual development, as well as in lipid metabolism and cognitive support in elderly individuals $[14,15]$.

If one takes into consideration that omega-3 fatty acids are necessary for the biosynthesis of eicosanoids such as prostaglandins (PG), thromboxanes (TX) and leukotrienes - lipid mediators that play a key role in vascular physiology -, it is possible assuming that DHA use in pregnant women can reduce vascular resistance, as well as facilitate the placentation process and maternal-fetal exchanges [16]. Interestingly, although, in theory, DHA's action mechanism is compatible with improved perfusion and oxygenation, many trials did not show these benefits in practice; therefore, further studies should be conducted [16,17]. In light of the foregoing, the aim of the current study was to evaluate the effect of omega 3/heparin association on pregnant women with thrombophilias, as well as its repercussions on placental vascular resistance and on maternalfetal outcomes.

\section{OBJECTIVES}

\section{Primary}

Evaluating uterine artery resistance in pregnant women with thrombophilia who were subjected to the herein selected treatment in association, or not, with omega.

\section{Secondary}

Evaluating the frequency of IUGR, fetal death and oligohydramnios, preeclampsia, PA, birth weight, prematurity and hospitalization in neonatal intensive care units (neonatal ICU) in pregnant women using, and not using, omega in association with heparin.

\section{PATIENTS AND METHODS}

This is a randomized, controlled, unblind, parallel, three-arm, open-label prevention trial conducted with pregnant women diagnosed with thrombophilia, who were treated in the Obstetrics Services of University Hospitals belonging to UFJF and to Medical School of Barbacena.

Patients were interviewed to collect data about clinical and epidemiological aspects such as number of pregnancies, childbirths and miscarriages, gestational age at the beginning of prenatal care, at childbirth, fetal weight and previous diseases [18]. 
Primary outcomes comprised high uterine artery resistance and preeclampsia, whereas secondary outcomes included fetal weight, hospitalization in neonatal ICU, fetal death, PA, Hellp Syndrome, fetal and neonatal death, miscarriage and IUGR.

All pregnant women had been previously diagnosed with thrombophilia. Any pregnant woman presenting one or more mutations in the following genes was classified as having hereditary thrombophilia: mutations in the MTHFR (C677T and/or A1298C) and prothrombin (G2020A) genes, as well as in factor $\mathrm{V}$ Leiden, and plasminogen inhibitor (PAI-1) polymorphism $(4 \mathrm{G} / 5 \mathrm{G})$. In addition to these mutations, patients with low $\mathrm{S}$ and $\mathrm{C}$ protein, and anti-thrombin III, concentrations were included in the study as having hereditary thrombophilias. With respect to acquired thrombophilia, any pregnant woman presenting lupus anticoagulant, anticardiolipin and/or anti B2 glycoprotein test results associated with maternal and/or fetal morbidity.

\section{All patients were divided into two groups:}

A. Group 1=Hereditary thrombophilia patients who used $40 \mathrm{mg}$ of heparin/day (enoxaparin) from the 6th pregnancy week on. These pregnant women were only treated with heparin, since they had no other indications for acetylsalicylic acid (ASA)-associated treatment.

B. Group $2=$ Patients with acquired or hereditary thrombophilias associated with risk factors for preeclampsia, according to ACOG [19] (chronic kidney disease, previous diabetes mellitus, chronic arterial hypertension and collagenoses). Thus, pregnant women in group 2 were treated with heparin, in association with ASA, as follows: group 2A (heparin+ASA) and group 2B (heparin+ASA+omega). The omega formulation given to the patients contained 5:1 DHA and EPA. The dosage was $400 \mathrm{mg} /$ day.

A sample calculation was based on data extracted from the Brazilian literature. The current study is a pilot project, which by definition is a small-scale test of the adopted procedures, materials and methods suggested for a given research. The number of participants in pilot studies does not need to exceed $10 \%$ of the target sample; based on this assumption, the minimum sample in the herein conducted pilot study comprised 28 pregnant women.

Doppler evaluation was performed at the 12 th pregnancy week, and between the 24th and the 28th pregnancy weeks, in order to assess uterine arteries. Patients were placed in supine, semisitting position, by keeping angles of $15^{\circ}$ and $30^{\circ}$ between them and the examination table to avoid vena cava compression. Next, images were generated, and Doppler mapping was performed. The transducer was longitudinally placed in the iliac fossa, parallel to the iliac crest and to the uterine wall, in order to identify the iliac vessels. Resistance $(\mathrm{RI})$ and pulsatility (PI=A-B/Mean) indices were the herein adopted hemodynamic indices. In addition, umbilical and middle cerebral artery dopplers were evaluated to investigate fetal conditions.

Data were digitized in electronic Access database forms, which were specifically developed for the current study. Results were expressed as mean and standard deviation (quantitative variables) and as absolute and relative frequencies (categorical variables). Statistical analyses were performed in the Statistical Package for Social Sciences (SPSS) software, version 13.0 for Windows (Chicago, IL, USA); Student's t-test was used to compare means between independent samples. Fischer's exact test was used to investigate association, whenever possible, and the $\chi^{2}$ test was applied to variables presenting more than two categories. All analyses were conducted at $5 \%$ significance level.

The current study was submitted to the Ethics Committee of Minas Gerais State Hospital Foundation and UFJF University Hospital. It is registered in the National Registry of Clinical Trials in Brazil.

\section{RESULTS}

The current study assessed 38 pregnant women treated at the Obstetrics Services of the Medical School of Federal University of Juiz de Fora and of Medical School of Barbacena. Patients' mean age was $32.9 \pm 5.0$ years, minimum age was 22 years and maximum age was 44 years. The mean number of successive pregnancies, childbirths and miscarriages was $2.8 \pm 1.6$ pregnancies, $0.7 \pm 0.7$ childbirths and 1.11 .6 miscarriages.

The analysis of previous diseases found 4 cases (10.5\%) of chronic arterial hypertension (CAH), 8 cases $(21.0 \%)$ of gestational diabetes mellitus (GDM), 2 cases (5.2\%) of type 1 diabetes and 1 case (2.6\%) of type 2 diabetes; 1 patient had hyperthyroidism $(2.6 \%)$ and 2 patients were nephropathic (5.2\%). Previous fetal death was identified in $34.2 \%$ of patients $(n=13)$ and previous preeclampsia in $15.8 \%$ of cases $(n=6)$ - data shown in Table 1 .

The pulsatility index in the second gestational trimester ( 24 to 28 weeks) was compared based on treatments. Patients treated with the $\mathrm{H}+\mathrm{ASA}+$ omega association recorded the lowest pulsatility index; however, there was not statistically significant difference between groups ( $\mathrm{p}>0.05)$. Results are shown in Table 2 .

Uterine artery resistance index in the second gestational trimester ( 24 to 28 weeks) was also compared based on treatments. Patients treated with the $\mathrm{H}+\mathrm{ASA}+$ omega association recorded the best resistance index, however, there was not statistically significant difference between groups ( $\mathrm{p}>0.05)$. Results are shown in Table 3.

Gestational diabetes $(n=8 ; 20.8 \%)$, preeclampsia $(n=2 ; 5.2 \%)$, premature labor $(n=1 ; 2.6 \%)$, gingival bleeding $(n=1 ; 2.6 \%)$ and

Table 1: Clinical and epidemiological aspects of the assessed patients.

\begin{tabular}{lcc}
\hline & Mean & Standard deviation \\
\hline Age & 33.0 & 5.0 \\
\hline Pregnancies & 2.8 & 1.6 \\
\hline Delivery & 0.7 & 0.7 \\
\hline Miscarriages & 1.2 & 1.6 \\
\hline Maternal diseases & $\mathrm{N}$ & $\%$ \\
\hline Hypertension & 4 & 10.5 \\
\hline Hyperthyroidism & 1 & 2.6 \\
\hline Previous diabetes & 3 & 7.9 \\
\hline Gestational diabetes & 8 & 21,1 \\
\hline Previous preeclampsia & 6 & 15.8 \\
\hline Previous fetal and maternal complications & 34,2 \\
\hline Previous fetal death & 13 & \\
\hline
\end{tabular}

Table 2: Uterine artery pulsatility index and its association with the adopted treatment (RUAPI: Right Uterine Artery Pulsatility Index; LUAPI: Left Uterine Artery Pulsatility Index; MPI: Mean Pulsatility Index; H: Heparin; ASA Acetylsalicylic Acid; O: Omega).

\begin{tabular}{ccccc}
\hline Group according to treatment & RUAPI & LUAPI & MPI & p value \\
\cline { 1 - 4 } H+ASA & $1.1 \pm 0.5$ & $1.1 \pm 0.2$ & $1.1 \pm 0.3$ & \multirow{2}{*}{0.3} \\
\cline { 1 - 3 } H+ASA+O & $0.7 \pm 0.4$ & $0.9 \pm 0.3$ & $0.8 \pm 0.3$ & \\
\cline { 1 - 3 } H & $0.9 \pm 0.5$ & $0.9 \pm 0.5$ & $0.9 \pm 0.5$ & \\
\cline { 1 - 2 }
\end{tabular}


Table 3: Uterine artery resistance index and its association with the adopted treatment (RUAPI: Right Uterine Artery Pulsatility Index; LUAPI: Left Uterine Artery Pulsatility Index; MPI: Mean Pulsatility Index; H: Heparin; ASA: Acetylsalicylic Acid; O: Omega).

\begin{tabular}{lcccc}
\hline Group according to treatment & RUAPI & LUAPI & MRI & p value \\
\cline { 1 - 4 } $\mathrm{H}+\mathrm{ASA}$ & $0.6 \pm 0.1$ & $0.6 \pm 0.1$ & $0.5 \pm 0.1$ & \multirow{2}{*}{0.5} \\
\cline { 1 - 4 } $\mathrm{H}+\mathrm{ASA}+\mathrm{O}$ & $0.4 \pm 0.1$ & $0.5 \pm 0.1$ & $0.5 \pm 0.1$ & \\
\cline { 1 - 4 } $\mathrm{H}$ & $0.5 \pm 0.1$ & $0.5 \pm 0.1$ & $0.4 \pm 0.2$ & \\
\hline
\end{tabular}

Table 4: Neonatal weight and its association with the selected treatment applied to patients.

\begin{tabular}{ccc}
\hline Group according to treatment & Neonatal weight & p value \\
\cline { 1 - 2 } $\mathrm{H}+\mathrm{ASA}$ & $2,963.7 \pm 187.3$ & \multirow{2}{*}{0.4} \\
\cline { 1 - 2 } $\mathrm{H}+\mathrm{ASA}+\mathrm{O}$ & $3,041.2 \pm 423.2$ & \\
\cline { 1 - 2 } $\mathrm{H}$ & $2,494.7 \pm 925.7$ & \\
\hline
\end{tabular}

thrombocytopenia $(n=1 ; 2.6 \%)$ stood out among the main prenatal complications. There were no IUGR or oligohydramnios cases.

Preeclampsia $(n=2 ; 5.2 \%)$, gestational diabetes with fetal repercussion $(n=3 ; 7.8 \%)$, nephropathy with maternal and fetal complications $(n=1 ; 2.6 \%)$ and premature labor $(n=1 ; 2.6 \%)$ stood out among the main complications leading to delivery. Three newborns had to be hospitalized in neonatal ICU (7.8\%), but all of them evolved satisfactorily. There was no neonatal or intrauterine fetal death. Mean fetal weight was 2,682 $\pm 779.9 \mathrm{~g}$; the lowest value was $715 \mathrm{~g}$, whereas the highest value was $3,505 \mathrm{~g}$. The association between neonatal weight and treatment is described in Table 4. The group treated only with heparin recorded the lowest fetal weight, although there was not statistically significant difference between groups.

\section{DISCUSSION}

The current study assessed 38 pregnant women. The results related to the number of pregnancies, deliveries and miscarriage are compatible with the literature, because since older women have longer menacme time and, consequently, they can present larger number of pregnancies, childbirths and miscarriages [1]. It is worth mentioning that the pregnant women included in the current study experienced risk pregnancy and, therefore, they were more prone to present risk pregnancy-associated diseases such as chronic arterial hypertension (CAH), hyperthyroidism, nephropathy and previous diabetes (DM). Thus, besides the herein evaluated disease (thrombophilia), it is essential taking into consideration other factors that can affect the obstetric outcome [1].

Patients treated with omega-associated treatment recorded reduced resistance in the uterine artery resistance and pulsatility indices, although there was not statistically significant difference between groups. This outcome is encouraging and interesting because it allows reasoning about the role played by omega as antioxidant and in reducing inflammatory processes to facilitate placentation and to enable good placental flow for proper fetal growth $[1,20]$. Such omega performance has been investigated and cited in several studies [21-23]. According to a study conducted in Egypt in 2016, omega has successfully increased the amount of amniotic fluid in patients presenting unexplained oligohydramnios. The aforementioned study has also found reduced uterine artery resistance and pulsatility indices; this outcome suggested that the increased amniotic fluid was associated with improved uterine flow [21]. Other studies have also proved that omega improved uterine artery perfusion in non-pregnant patients [22]. Importantly, animal models treated with heparin also recorded reduced uterine artery resistance and pulsatility indices [23]. Thus, ASA+omega association with heparin appears to play a key role in reducing these indices, in optimizing uterine flow and in providing good oxygen supply to the fetus. This outcome stands out if one takes into consideration the mean weight of newborns, which was significantly higher in patients treated with heparin+omega+ASA association.

Gestational diabetes, preeclampsia, premature labor, gingival bleeding and thrombocytopenia were the main prenatal complications observed in the current study; there were no IUGR and oligohydramnios cases. However, although gingival bleeding was associated with anticoagulant use, there were no major complications resulting from such association; this outcome suggests that adequate prenatal care helps reducing the number of maternal and fetal complications [1]. Although complications resulting from heparin use have already been reported, the current study did not record any case of vaginal bleeding or need to withdraw the medication; this outcome shows that the use of prophylactic heparin doses, even in association with omega and/ or ASA, is relatively safe during pregnancy. There was no neonatal or intrauterine fetal death case. There were no differences in the frequency of preeclampsia, Hellp syndrome or gestational diabetes between groups.

Although the current research is a pilot study, its results are relevant and show that the use of omega, in combination with ASA, can increase uterine plasma flow and optimize newborn weight in pregnant women with thrombophilia who are treated with heparin. However, these results deserve to be further investigated in an expanded study that includes another group of pregnant women (heparin+omega users). This expanded study is already in progress in our service and its results, although incipient, provide an optimistic perspective about the use of omega by pregnant women with thrombophilia.

\section{CONCLUSION}

Our results are preliminary, and a crude evaluation of the data shows a decrease in the pulsatility and resistance indices of the uterine artery. With the increase of patients in the analysis, we hope that the statistical results can demonstrate this improvement of placental flow.

\section{REFERENCES}

1. Andrade JR, Camargos MV, Reis MFR, Maciel RAB, Melo TT, Batalha SH, et al. A história obstétrica de gestantes com trombofilias hereditárias. Clin Biomed Res. 2019.

2. Altuna D, Ceresetto J, Fassi D, Ferro H, Fondevila C, Giumelli C, et al. Trombofilias. Argentina: Sociedade Argentina de Hematologia;2018. p: 481.

3. Rades E, Bittar RE, Carvalho MHB, Martinelli S, Femina ZM. A história obstétrica de gestantes com trombofilias hereditárias. Clin Biomed Res. 2007;35(9): 573-578.

4. Preston FE, Rosendaal FR, Walker ID, Briet E, Berntorp E, Conard J, et al. Increased fetal loss in women with heritable thrombophilia. Obstet Gynecol Surv. 1997;52(3):155-156.

5. Almeida JMF. Trombofilia hereditária e gravidez: controvérsias actuais, 2010.

6. Bates SM, Greer IA, PabingerI, Sofaer S, Hirsh J. Venous 
thromboembolism, thrombophilia, antithrombotic therapy, and pregnancy: American college of chest physicians evidence-based clinical practice guidelines (8th edition). Chest. 2008;133(6): 844-886.

7. Robertson L, Wu O, Langhorne P, Twaddle S, Clark P, Lowe GD, et al. Thrombophilia in pregnancy: A systematic review. Br J Haematol. 2006;132(2):171-196.

8. Burla M, Braga A, Coulamy LB, Oliveira T, Silva EP, Vasques F. Abortamento de repetição. Revista do hospital universitário pedro ernesto. 2015;14(2):34-39.

9. Barros VIPVL, Igai AMK, Andres MP, Francisco RP, Zugaib M. Resultados gestacionais e trombofilias em mulheres com história de óbito fetal de repetição. Rev Bras Ginecol. Obstet. 2018;36(2): 50-55.

10. Oliveira MC. Trombofilia hereditária: Contribuição de factores genéticos para a predisposição de Tromboembolismo Venoso na população da região centro de Portugal. Dissertação apresentada à Faculdade de Ciências e Tecnologia da Universidade de Coimbra para obtenção do grau de Mestre em Biologia Animal.

11. Sete MRC, Figueredo CMS. Periodontite e ômega 3: O papel dos ácidos graxos no processo inflamatório. Braz J of Health Biomed Sci, 2013.

12. Bessa V. Ácidos gordos ómega-3 na gravidez. Faculdade de Ciências da Nutrição e Alimentação da Universidade do Porto, 2012.

13. Silva DRB, Junior PFM, Soares EA. A importância dos ácidos graxos poliinsaturados de cadeia longa na gestação e lactação. Rev Bras Saúde Matern Infant. 2007;7(2):123-133.

14. Garofolo A, Petrilli AS. Balanço entre ácidos graxos ômega-3 e 6 na resposta inflamatória em pacientes com câncer e caquexia. Rev Nutr. 2006;19(5): 611-621.
15. Santos ES, Silva DMF, Frotal DC, Garcia YR. Uso de ácidos graxos poli-insaturados durante a gestação: Um estudo bibliográfico. REAS/ EJCH. 2018;11(1): 1-10.

16. Burchakov DI, Kuznetsova IV, Uspenskaya YB. Omega-3 long-chain polyunsaturated fatty acids and preeclampsia: Trials say "no," but is it the final word? Nutrients, 2017.

17. Kemse N, Sundrani D, Kale A, Joshi S. Maternal micronutrients, omega-3 fatty acids and gene expression of angiogenic and inflammatory markers in pregnancy induced hypertension rats. Arch Med Res. 2017;48(5): 414-422.

18. Federação Brasileira das Associações de Ginecologia e Obstetrícia (FEBRASGO). Ficha clínica de pré-natal.

19. ACOG Statement on USPSTF Final Recommendations on Screening for Preeclampsia, 2017.

20. Barros VIPVL, Igai AMK, Andres MP, Francisco RPV, Zugaib M. Resultados gestacionais e trombofilias em mulheres com história de óbito fetal de repetição. Rev Bras Ginecol Obstet. 2014;36(2): 50-55.

21. Ismail AM, Ramadan MF, Ali MK, Abbas AM, El Saman AM, Makarem MH. A randomized controlled study of the efficacy of 4 weeks of supplementation with $\omega-3$ polyunsaturated fatty acids in cases of unexplained oligohydramnios. J Perinatol. 2016;36(11): 944-947.

22. Lazzarin N, Vaquero E, Exacoustos C, Bertonotti E, Romanini ME, Arduini D. Low-dose aspirin and omega-3 fatty acids improve uterine artery blood flow velocity in women with recurrent miscarriage due to impaired uterine perfusion. Fertil Steril. 2009;92(1): 296-300.

23. Senefonte FRA, Aydos RD, Oliveira VM, Bosio MAC, Figuieró-Filho EA. Doppler velocimetry in fetal rats exposed to enoxaparin and unfractionated heparin (UFH) during pregnancy. Acta Cir Bras. 2017: 32(5): 325-333. 